\title{
ROTAS TURÍSTICAS EM REGIÕES VINÍCOLAS: ENOTURISMO NA CAMPANHA DO RIO GRANDE DO SUL - BRASIL
}

TOURISTIC ROUTES IN WINERIES REGIONS: ENOTOURISM IN CAMPANHA REGION RIO GRANDE DO SUL - BRAZIL

RUTAS TURÍSTICAS EN REGIONES VINICOLAS: ENOTURISMO EN LA CAMPAÑA DEL RIO GRANDE DO SUL - BRASIL

Fabrício Silva Barbosa

Docente do Eixo Tecnológico Turismo, Hospitalidade e Lazer no Instituto Federal de Ciência e Tecnologia Farroupilha - Campus São Borja - RS. Mestre em Planejamento do Turismo e da Hotelaria - (UNIVALI/2010) Doutorando em Engenharia de Produção e Sistemas - (UNISINOS) fabricio.barbosa@iffarroupilha.edu.br

\section{Daniel Pacheco Lacerda}

Doutor em Engenharia de Produção pela COPPE/UFRJ, Mestre em Administração pela Universidade do Vale do Rio dos Sinos (2005) e Bacharel em Administração de Empresas - Instituição Educacional São Judas Tadeu (2002)

Dlacerda@unisinos.br

\section{Cláudia Viviane Viegas}

Doutora em Engenharia e Gestão do Conhecimento pela Universidade Federal de Santa Catarina (UFSC), Mestre em Administração/Gestão Ambiental pela Universidade Federal do Rio Grande do Sul (UFRGS) claudiaVV@unisinos.br 
Alessandra Santos dos Santos

\author{
Docente do Curso Superior de Tecnologia em Gastronomia - Centro Universitário \\ de Brasília (UniCEUB) e do Curso de Bacharelado em Turismo - Centro de Excelência \\ em Turismo/ Universidade de Brasília (CET/UnB) \\ Mestre em Turismo e Hotelaria (UNIVALI/2008 \\ Alessandra.santos@uniceub.br \\ Data de Submissão: 06/08/2016 \\ Data de Aprovação: 03/11/2016
}

\begin{abstract}
RESUMO: O Enoturismo emergiu como um rentável setor agroindustrial, responsável por fomentar o desenvolvimento regional especialmente econômico de regiões produtoras de vinho. Em virtude do crescimento e desenvolvimento desta atividade, novos destinos turísticos estão surgindo e, com isso, novos meios econômicos emergem para atrair apreciadores, consumidores ou não de vinhos, fazendo com que o patrimônio cultural vinícola seja resgatado e mantido. Muitas das pesquisas realizadas acerca do enoturismo sugerem os benefícios desta atividade para a indústria do vinho, assim como para as localidades rurais envolvidas. Nesta perspectiva, o presente trabalho tem como objetivo analisar o Enoturismo como atividade econômica, e o quanto este contribui para o desenvolvimento de vinícolas localizadas na Região da Campanha do Estado do Rio Grande do Sul - Brasil. Para a realização dessa investigação optou-se pela elaboração de pesquisa com abordagem qualitativa, utilizando como método a estruturação de um estudo de caso descritivo, com análise de conteúdo a partir de entrevista estruturada. Os resultados apontam o Enoturismo em curva crescente em todas as empresas estudadas, atuando como ferramenta de competitividade de vinícolas locais, contribuindo para o fortalecimento da marca e comercialização de seus produtos.
\end{abstract}

PALAVRAS CHAVES: Serviços. Enoturismo. Competitividade.

ABSTRACT: Enotourism has emerged as a profitable agroindustrial field, responsible for putting forward the regional development, mainly economic, of regions that produce wine. Given the growth and development of such activity, new touristic destinations are arisen, so that new economic means emerge in order to attract appreciators, whether wine customers, or not. It entails the preservation, and even the rescue, of the cultural winery heritage. Several researches on enotourism suggest benefits of this activity to the wine industry, as well as to the involved rural places. Under such perspective, this research has as aim to analyze the enotourism while economic activity, and how much it contributes to the development of wineries placed at the Campanha Region in Rio Grande do Sul State, Brazil. The unities of analysis are placed at South-weast of Rio Grande do Sul, embracing almost all the border between Brazil and Uruguay, and part of the border between Brazil and Argentina. It comprises an area with 19 municipalities of Rio Grande do Sul. To perform this investigation, a qualitative approach was selected, with the employment of a structured case study, embedding contente analysis from structured interviews. Results show that enotourism has an upsweep in all studied firms, acting as a competitive tool for the local wineries, and given contribution to the strenghteningof the brands and products selling.

KEY WORDS: Services. Enotourism. Competitiveness. 
RESUMEN: El enoturismo ha surgido como un campo agroindustrial rentable, responsable de impulsar el desarrollo regional, principalmente económico, de las regiones productoras de vino. Dado el crecimiento y el desarrollo de esta actividad, surgen nuevos destinos turísticos, de modo que surgen nuevos medios económicos para atraer apreciadores, sean o no clientes del vino. Implica la preservación, e incluso el rescate, del patrimonio cultural de la bodega. Varias investigaciones sobre el enoturismo sugieren beneficios de esta actividad a la industria vitivinícola, así como a los lugares rurales involucrados. Bajo esta perspectiva, esta investigación tiene como objetivo analizar el enoturismo mientras la actividad económica, y cuánto contribuye al desarrollo de bodegas ubicadas en la Región de Campanha en el Estado de Rio Grande do Sul, Brasil. Las unidades de análisis están ubicadas al sul de Río Grande do Sul, abarcando casi toda la frontera entre Brasil y Uruguay, y parte de la frontera entre Brasil y Argentina. Comprende un área con 19 municipios de Rio Grande do Sul. Para realizar esta investigación se seleccionó un enfoque cualitativo, con el empleo de un estudio de caso estructurado, incorporando el análisis de contento a partir de entrevistas estructuradas. Los resultados demuestran que el enoturismo tiene una tendencia ascendente en todas las empresas estudiadas, actuando como una herramienta competitiva para las bodegas locales y contribuyendo al fortalecimiento de las marcas y productos vendidos.

PALABRAS CLAVE: Servicios. Enoturismo. Competitividad.

\section{INTRODUÇÃO}

representativo crescimento do Enoturismo em nível global nas últimas décadas tem possibilitado que localidades rurais desenvolvam uma nova atividade que estimule o desenvolvimento econômico, oferecendo aos viajantes a oportunidade de desfrutar de uma experiência que envolve conhecimentos culturais e gastronômicos (Alonso; Liu, 2010).

É notável o aumento de turistas interessados em consumir o produto vinho. Em alguns lugares as vinícolas, as rotas de vinhos e os processos que envolvem a sua produção são os principais atrativos (Byrd et al, 2016). Os estudos e pesquisas que envolvem o Enoturismo estão alicerçados em três pilares: as disposições do produto, estratégias de comercialização e a experiência do visitante na destinação (Qiu et al, 2013).

O conceito de Enoturismo tem sido objeto de diversos estudos e pesquisas, não apenas pelo crescimento da atividade como promotora da viticultura, mas também como pelo crescimento da mesma enquanto atividade turística. As principais contribuições da literatura que buscam compreender esta tipologia de turismo enquanto ferramenta de promoção do vinho, assim como uma segmentação da atividade turística foram desenvolvidas na Austrália, Nova Zelândia, Estados Unidos e Canadá (Tomasetti; Festa, 2014). 
A definição mais aceita de Enoturismo é explicada por Hall et al (2000) como sendo atividades que envolvem visitas a vinícolas, vinhedos, shows e festivais de vinhos, permitindo aos atores envolvidos a possibilidade de degustação dos vinhos e a experiência de uma região que tem a uva como principal atrativo para os turistas.

Lopéz-Guzmán et al (2011) afirmam que a combinação do Turismo e do Vinho permite que os turistas, ao apreciarem este produto distinto, contribuam com a promoção e com o desenvolvimento econômico das regiões produtoras de vinho, que ocorre ou pela visitação aos vinhedos ou pelas vendas realizadas nas vinícolas.

A literatura aponta para a realização de algumas pesquisas sobre Enoturismo. Dentre os estudos identificados por Mitchell e Hall (2006), os principais são: o Enoturismo como produto, o papel do Enoturismo no desenvolvimento regional, a motivação dos turistas apreciadores do Enoturismo, comportamento do consumidor de vinhos, a natureza das visitas a vinícolas, segurança alimentar em vinícolas e quantificação da demanda de visitantes. Contudo, a maioria das pesquisas sobre o Turismo do vinho tem limitado suas contribuições, sobretudo, às motivações que levam o viajante a optar por este segmento do turismo (Cho et al, 2014).

Dentre as lacunas encontradas na literatura específica sobre o Turismo do vinho foi identificada a necessidade de trabalhos que apresentem quais os principais obstáculos que fazem os viajantes desistirem de conhecer uma vinícola. Outra lacuna verificada é a necessidade de estudos formais que demonstrem como o enoturismo tem contribuído no processo de transformação de áreas rurais em destinações turísticas (Marzo-Navarro; Pedraja-Iglesias, 2012; Koch et al, 2013).

Nesta perspectiva, o presente trabalho tem como objetivo analisar de que forma o Enoturismo enquanto atividade econômica contribui para o desenvolvimento de vinícolas localizadas na Região da Campanha no estado do Rio Grande do Sul - Brasil. A pesquisa foi realizada tomando como unidade de análise vinícolas localizadas na região da Campanha. Esta região encontrase no sudoeste do Rio Grande do Sul, abrange quase que em sua totalidade a linha de fronteira com o Uruguai e parte da fronteira com a Argentina em uma 
área que totaliza 19 municípios gaúchos (REDVIN, 2016). Na divisão turística do estado, a Campanha se situa na região dos Pampas, onde se desenvolveu a vitivinicultura contando atualmente com aproximadamente 16 vinícolas. (SETUR, 2016; REDVIN, 2016).

Para a concretização deste trabalho optou-se pela realização de uma pesquisa com abordagem qualitativa, utilizando como método de pesquisa a estruturação de um estudo de caso descritivo. Os resultados da pesquisa apontam o Enoturismo em curva crescente em todas as empresas estudadas, atuando como ferramenta de competitividade de vinícolas locais, contribuindo para o fortalecimento da marca e comercialização de seus produtos.

A pertinência acadêmica deste trabalho justifica-se a partir da ausência de estudos formais junto à literatura específica que venham contribuir para uma melhor compreensão do fenômeno que envolve o Turismo do Vinho.

\section{ENOTURISMO: DEFINIÇÕES E TENDÊNCIAS}

As primeiras investigações acerca do enoturismo tiveram como ponto de partida estudos realizados na Austrália e na Nova Zelândia na década de 1990. Estes estudos versaram principalmente sobre a contribuição econômica do enoturismo para o desenvolvimento de zonas rurais, e sobre o comportamento dos turistas apreciadores desta atividade (López-Guzmán et al, 2013).

São representativos os estudos realizados em nível mundial com objetivo de compreender e ao mesmo tempo analisar os impactos econômicos ocasionados pelo crescimento do fenômeno Enoturismo. O turismo do vinho tem sido estudado por diversos pesquisadores oriundos da Austrália, Canadá, Chile, França, Alemanha, Nova Zelândia, África do Sul, Estados Unidos, Espanha e Itália (Jones et al, 2015).

O enoturismo tem emergido como um setor industrial rentável capaz de gerar desenvolvimento econômico e transformar diversas regiões produtoras de vinhos em destinos turísticos (Marzo-Navarro; Pedraja-Iglesias, 2012). Dawson et al (2011) afirmam que o turismo corresponde a uma experiência que envolve estilo de vida e desenvolvimento pessoal. Para os autores o enoturismo converte-se em uma alternativa para promoção de relacionamento entre as vinícolas e os consumidores. 
O enoturismo está ligado diretamente ao turismo rural. É um fenômeno global que envolve a busca de um determinado local, evento ou destino cultural que tenha o vinho como atrativo principal, sendo que os impactos econômicos nestas localidades são significativos (Quadri-Felitti; Fiore, 2012). Goméz et al (2013) afirmam que nos últimos anos diversas áreas rurais têm passado por diversas transformações em especial na infraestrutura, a fim de atender uma nova demanda do mercado turístico.

Alonso e Liu (2010) afirmam que a combinação do vinho juntamente com o turismo tem como resultado uma importante ferramenta de competitividade capaz de promover localidades, sejam elas turísticas ou não, atrativos e comunidades rurais criando uma identidade para os mesmos. Tomasetti e Festa (2014) sugerem outra combinação que consideram fundamental para o crescimento da indústria do vinho: comida e turismo, isso quando considerada apenas a perspectiva de cultivo de uvas e produção de vinhos em pequena escala.

Marzo-Navarro e Pedraja-Iglesias (2012) afirmam que o enoturismo contribui com a indústria do vinho no sentido de fortalecer as relações entre as vinícolas e os clientes atuais e em potenciais interessados em adquirir experiências no segmento da vitivinicultura, além de fortalecerem suas marcas e possibilitar a venda direta aos clientes, o que resulta em aumento do fluxo de receitas.

A literatura contemporânea tem procurado diversas formas de definir o Turismo do Vinho, dentre elas a mais aceita é de que o enoturismo contemplaria atividades de visitação a vinhedos, adegas, festivais e shows de vinhos para qual a degustação de vinhos, assim como a experiência em regiões produtoras de vinhos seriam as principais motivações (Hojman; Hunter-Jones, 2012).

Grybovych et al (2013) afirmam que o fenômeno Enoturismo não consiste apenas em visitar vinícolas e comprar vinhos. Para os autores, o turismo do vinho é uma experiência única que envolve paisagem, ambiente, cultura e gastronomia. São os atributos específicos do vinho que são determinantes na construção da identidade buscada pelas comunidades rurais que buscam no enoturismo uma possibilidade de desenvolvimento.

Clemente, Ricolfe et al (2012) elencam diversas atividades relacionadas ao enoturismo. Estas experiências podem ser aproveitadas pelos turistas durante a visita ao destino e vão ao encontro dos conceitos de enoturismo apresentados nesta sessão. São elas: compra de vinhos, degustação de vinhos, visita aos 
vinhedos, orientações acerca da produção do vinho, participação em refeições temáticas, visitas a feiras, museus e festivais de vinhos.

Os estudos de Cho et al (2014) procuram descrever as principais motivações responsáveis pelo deslocamento de turistas a vinícolas e vinhedos. Os autores apontam que o interesse em degustar diferentes tipos de vinhos nos locais onde são produzidos é a principal delas. Outras motivações que justificam o interesse pelo turismo do vinho são: a busca sobre informações globais acerca dos processos que envolvem a produção do vinho e a paisagem que envolve a atmosfera dos vinhedos que neste processo são complementares no conjunto de serviços entregues aos visitantes.

Os estudos de Carlsen e Boksberger (2015) identificaram os principais fatores que compõem a experiência total enoturística, seriam elas: a interação existente entre os serviços, o mix existente na oferta de produtos, experiências que resultam em crescimento pessoal, estilo de vida e a disseminação de informações sobre o lugar e o seu entorno.

O crescimento do enoturismo na América do Sul ratifica-se quando verificados os números de turistas que visitaram a macrorregião enoturística formada pelos seguintes países: Argentina, Chile, Brasil e Uruguai. Os números apontam que cerca de 1,2 milhões de turistas visitaram as vinícolas sulamericanas, com destaque para os empreendimentos localizados na região de Mendoza, na Argentina, que atualmente abriga aproximadamente 116 vinícolas (Ashton et al, 2015).

Zanini e Rocha (2010) afirmam que no Brasil o enoturismo se desenvolve à medida em que a vitivinicultura nacional evolui em qualidade. Este indicativo também reflete a quantidade de estudos formais realizados por pesquisadores brasileiros que buscam uma maior compreensão do fenômeno.

No Brasil, o enoturismo tem manifestações na região nordeste e no sul do país onde se encontra consolidado na região do Vale dos Vinhedos, principal região produtora de vinhos do país, localizada no Estado do Rio Grande do Sul.

A literatura específica sugere que o enoturismo nasceu nesta região há cerca de quarenta anos transformando-se em importante atividade econômica para os municípios que formam o Vale dos Vinhedos (Ashton et al, 2015).

O quadro 01 a seguir sintetiza os principais trabalhos e autores consultados para construção desta seção. 
Quadro 1: Síntese da Base Teórica

\begin{tabular}{|c|c|c|}
\hline Constructo & Conceito & Autor(es) \\
\hline Enoturismo & $\begin{array}{l}\text { Pesquisas e tendências. } \\
\text { Mercado. } \\
\text { Enoturismo no contexto rural. } \\
\text { Enoturismo enquanto } \\
\text { experiência. }\end{array}$ & $\begin{array}{l}\text { - López-Guzmán et al, 2013; Marzo- } \\
\text { Navarro; Pedraja-Iglesias, } 2012 . \\
\text { - Ashton et al, 2015; Getz \& Brown, } \\
\text { 2006; Hall et AL, 2000; Clemente- } \\
\text { Ricolfe et al, 2012; Zanini; Rocha, } \\
\text { 2010. } \\
\text { - Hojman, D. E., \& Hunter-Jones, P. } \\
\text { (2012); } \\
\text { - Grybovych et al (2013); } \\
\text { - Hall et al (2000); Alonso e Liu } \\
\text { (2010); Tomasetti e Festa (2014). }\end{array}$ \\
\hline
\end{tabular}

Fonte: Elaborado pelo Autor (2016).

\section{PROCEDIMENTOS METODOLÓGICOS}

Esta pesquisa é de caráter qualitativo, descritiva, com aplicação de estudo de caso como método. Flick (2004) afirma que alguns aspectos que diferenciam a pesquisa qualitativa da pesquisa quantitativa devem ser considerados, dentre eles: a habilidade do pesquisador no que tange o método de pesquisa, assim como a utilização de teorias que estejam de acordo com o fenômeno estudado e a identificação de diferentes perspectivas do objeto estudado.

A pesquisa qualitativa está focada na obtenção de informações dos indivíduos, assim como nas interpretações do ambiente. Tende a ser menos estruturada e privilegiar a interpretação subjetiva dos atores envolvidos e os processos que conduzem aos resultados (Cauchick-Miguel, 2012).

A utilização do estudo de caso como método de pesquisa justifica-se por esta investigação de natureza empírica remeter a formulações de reflexões do tipo "como" e "por que", além de se tratar de uma temática de pouco conhecimento por parte do pesquisador (Yin, 2010).

Para Voss et al (2002), o estudo de caso é um dos métodos mais utilizados em pesquisas que envolvem Gestão de Operações tendo aplicabilidade no detalhamento de problemas que ainda não foram claramente estabelecidos. Eisenhardt (1989) ratifica este pensamento afirmando que o estudo de caso é viável em pesquisas que não tiveram suas temáticas de estudos aprofundadas.

Para construção da metodologia desta investigação, inicialmente realizou-se uma revisão sistemática da literatura nas bases de dados Ebsco, Proquest e Capes. 
Conforto et al (2011) explicam que a revisão sistemática tem o seu reconhecimento como sendo clara, detalhada e de fácil replicabilidade. Os autores afirmam ainda que este tipo de pesquisa é frequentemente utilizado em investigações da área da saúde e recentemente vem sendo utilizada na área de gestão.

O recorte temporal buscou identificar pesquisas realizadas no período compreendido entre 2011 a 2016. As palavras-chaves utilizadas foram: enoturismo, vitivinicultura, turismo e competitividade. A pesquisa foi realizada fazendo uso dos termos em Inglês e em Português.

Finalizada a revisão sistemática, identificaram-se alguns gaps que possibilitaram a delimitação do objetivo desta pesquisa. A segunda parte do processo de construção da metodologia teve como foco a estruturação do protocolo de pesquisa composto por quatorze questões abertas, elaborado a partir do constructo Enoturismo. Este constructo norteou a revisão da literatura apresentada na sessão anterior.

A coleta de dados primários foi obtida por meio da realização de entrevistas com os diretores de quatro vinícolas localizadas na Região da Campanha Gaúcha. A entrevista é a técnica que permite ao pesquisador explorar amplamente uma determinada questão, visto que o principal valor está na profundidade das informações e nos detalhes a serem obtidos (Cooper e Schindler, 2003).

A pesquisa foi complementada com dados secundários obtidos nos documentos fornecidos pelos entrevistados, e também por meio de informações encontradas no website das empresas pesquisadas.

Para realizar a apreciação dos dados coletados, foi utilizada a análise de conteúdo, para estruturar e sistematizar os documentos oficiais e as questões abertas da entrevista, que reproduziram uma base de dados, com diversas variáveis. Estas permitiram identificar aspectos comuns e distintos entre as vinícolas, retratando de forma verídica o significado da pesquisa (Franco, 2005).

A análise qualitativa dos dados foi realizada a partir da estruturação das análises de categorias priorizando os elementos chaves apresentados na revisão da literatura e protocolo de pesquisa: enoturismo.

As interpretações deste tipo de pesquisa são construídas ao longo do processo, porém já imaginadas no planejamento da pesquisa, por meio da questão norteadora e do objeto a ser investigado. 
RESULTADOS DA PESQUISA

\section{CARACTERIZAÇÃO DA UNIDADE DE ANÁLISE}

A região da Campanha Gaúcha corresponde a uma faixa localizada na fronteira do Brasil com o Uruguai. Esta região apresenta clima favorável para o cultivo da viticultura, em especial de uvas europeias, o que tem contribuído para que a região se destaque na produção de vinhos de qualidade no cenário nacional e internacional (ACADEMIADOVINHO, 2016). A Região da Campanha Gaúcha possui como referência os municípios de: Dom Pedrito, Candiota, Bagé e Santana do Livramento. Contudo, a localidade abrange aproximadamente 19 municípios do estado do Rio Grande do Sul (ACADEMIADOVINHO, 2016; REDVIN, 2016).

As vinícolas pesquisadas nesta investigação são caracterizadas como empreendimentos de pequeno e médio porte. As empresas estão localizadas nos municípios de Bagé, Itaqui, Dom Pedrito e Candiota, conforme os dados que serão apresentados na próxima sessão. Apenas um destes empreendimentos não recebe visitantes, contudo, de acordo com o diretor da empresa, existe demanda para a realização de atividades ligadas ao enoturismo.

A figura 1 apresenta a localização geográfica da microrregião da Campanha Gaúcha:

Figura 1: Local das Vinícolas da Campanha Gaúcha

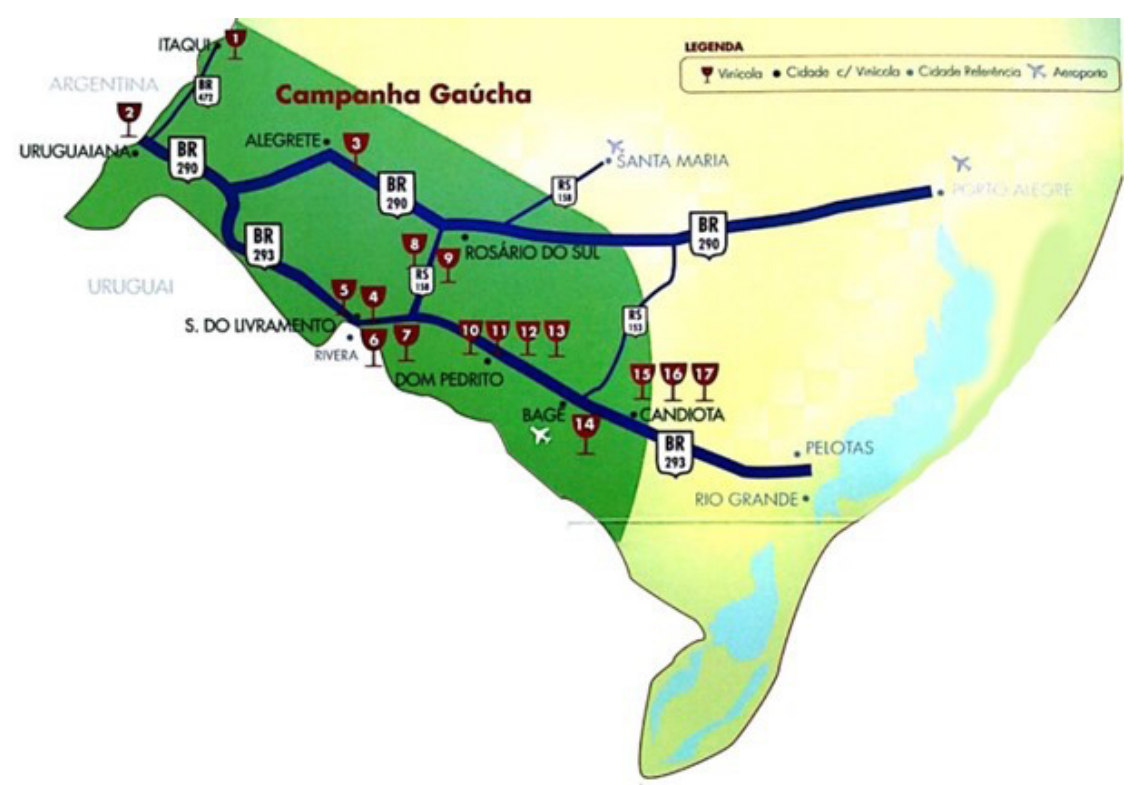




\section{APRESENTAÇÃO DOS DADOS COLETADOS}

\begin{tabular}{|c|c|c|c|c|}
\hline Enoturismo & Empresa A & Empresa B & Empresa C & Empresa D \\
\hline Mercado & \begin{tabular}{|c|} 
Iniciou o recebimento de \\
turistas no ano de 2015 . A \\
empresa somente decidiu \\
receber visitantes a partir do \\
momento em que passou a \\
possuir estrutura adequada \\
para receber os viajantes de \\
forma satisfatória. \\
A empresa estudou \\
modelos de vinícolas \\
localizadas na Argentina, \\
França, Uruguai e Portugal. \\
A empresa faz uso de \\
todas as ferramentas \\
de comunicação \\
para divulgação do \\
empreendimento, em \\
especial as ferramentas \\
de comunicação digital. \\
Ainda não atua em parceria \\
com agência de viagens \\
para captação de turistas, \\
porém tem interesse em \\
firmar parcerias futuras para \\
captação de visitantes. De \\
acordo com o respondente \\
a empresa está construindo \\
alojamentos na área da \\
vinícola, que será mais um \\
diferencial para captação \\
de turistas apreciadores de \\
vinhos. \\
A empresa recebe \\
visitantes o ano inteiro, \\
sem necessidade de \\
agendamentos. Segundo \\
o diretor comercial da \\
vinícola os agendamentos \\
são necessários apenas \\
quando envolvem \\
atividades gastronômicas, \\
de harmonização de \\
vinhos e possibilidades de \\
participação na colheita das \\
uvas.
\end{tabular} & \begin{tabular}{|} 
A vinícola iniciou o \\
recebimento de turistas \\
no ano de 2013, quando \\
identificou o potencial do \\
enoturismo. A empresa \\
iniciou suas atividades \\
através de uma parceria \\
realizada com a Prefeitura \\
Municipal e o DNIT. \\
O modelo adotado para \\
estruturação da vinícola \\
é o modelo das vinícolas \\
da Serra Gaúcha. \\
A empresa trabalha em \\
parceria com algumas \\
agências de viagens. \\
Porém, a maioria dos \\
turistas que visitam a \\
vinícola são clientes \\
captados de forma direta. \\
O empreendimento \\
recebe visitas durante \\
o ano todo que \\
incluem degustações e \\
informações acerca da \\
vitivinicultura. \\
Estas atividades \\
não necessitam de \\
agendamento \\
prévio, exceto para \\
realização de refeições na \\
vinícola, em que se exige \\
agendamento e grupos \\
com número mínimo de \\
20 participantes. \\
A respondente informou \\
que atualmente não \\
existem projetos de \\
novos investimentos \\
na empresa. Existe, sim, \\
interesse em melhorar a \\
infraestrutura existente, \\
assim como os serviços \\
que já são oferecidos.
\end{tabular} & $\begin{array}{c}\text { A empresa iniciou o } \\
\text { recebimento de visitantes } \\
\text { no ano de 2013, momento } \\
\text { este em que foi identificado } \\
\text { o potencial da região para } \\
\text { o desenvolvimento do } \\
\text { turismo do vinho. A empresa } \\
\text { possui parceria com agência } \\
\text { de viagens e operadores } \\
\text { de turismo, sendo que a } \\
\text { maior parte dos turistas que } \\
\text { visitam a vinícola é oriunda } \\
\text { de estratégias de captação } \\
\text { direta de clientes. As principais } \\
\text { ferramentas de promoção da } \\
\text { empresa são as redes sociais } \\
\text { material impresso, website e } \\
\text { assessoria de imprensa, além } \\
\text { da produção periódica de } \\
\text { campanhas publicitárias que } \\
\text { têm como objetivo principal } \\
\text { a promoção e divulgação do } \\
\text { empreendimento em nível } \\
\text { nacional e internacional. } \\
\text { A empresa estudou modelos } \\
\text { de vinícolas localizadas na } \\
\text { Califórnia, Uruguai, Argentina } \\
\text { e Chile para que então se } \\
\text { chegasse a sua estrutura atual. } \\
\text { A vinícola recebe visitantes } \\
\text { durante o ano todo sem } \\
\text { necessidade de agendamento } \\
\text { prévio com a empresa. Todos } \\
\text { os programas relacionados } \\
\text { com o enoturismo oferecidos } \\
\text { estão disponíveis no website da } \\
\text { empresa. } \\
\text { Os principais serviços oferecidos } \\
\text { aos visitantes são: tour rural } \\
\text { realizado nas dependências da } \\
\text { vinícola, degustação de vinhos } \\
\text { e refeições harmonizadas. } \\
\text { De acordo com a diretora do } \\
\text { empreendimento atualmente } \\
\text { não existem novos projetos } \\
\text { para expansão da empresa, pois } \\
\text { a atual infraestrutura da vinícola } \\
\text { atende as demandas existentes. }\end{array}$ & \begin{tabular}{|c|} 
A empresa não \\
recebe visitantes em \\
suas dependências. \\
De acordo com \\
sócio proprietário \\
da vinícola, o \\
empreendimento \\
está localizado \\
dentro de uma \\
propriedade atuante \\
no segmento de \\
gado de corte, \\
não possuindo \\
infraestrutura \\
necessária para \\
receber turistas. \\
A vinícola recebe \\
somente grupos \\
de profissionais \\
(sommeliers, \\
enólogos e \\
jornalistas), que \\
realizam visitas pré- \\
agendadas. Contudo, \\
o respondente \\
afirma que mesmo \\
não recebendo \\
visitantes em sua \\
propriedade, a \\
demanda de procura \\
é considerada alta. \\
O diretor da \\
empresa informou \\
que existe interesse \\
na construção de \\
um espaço com \\
toda infraestrutura \\
adequada para \\
receber visitantes, \\
uma vez que \\
considera o \\
enoturismo como \\
uma atividade \\
de extrema \\
importância para o \\
desenvolvimento \\
regional e \\
econômico \\
da Região da \\
Campanha. \\
\end{tabular} \\
\hline
\end{tabular}




\section{Motivações dos visitantes}

Fluxo de Turistas
De acordo com o entrevistado, as principais motivações dos visitantes estão relacionadas com: a curiosidade de se conhecer 0 funcionamento de uma vinícola, conhecer a região, apreciar e degustar diferentes tipos de vinhos. As principais limitações estão ligadas à distância da vinícola (aproximadamente $550 \mathrm{~km}$ da capital), e à falta de infraestrutura turística na cidade para recebimento de turistas. Há também dificuldades por parte da comunidade local, em compreender que produtos e serviços diferenciados podem exigir um investimento maior por parte do cliente.
Para a respondente as principais motivações dos visitantes são: o desejo de conhecer o funcionamento de uma vinícola, assim como o de degustar vinhos de qualidade.

Outra motivação apontada na pesquisa é a possibilidade da compra de vinhos de boa procedência e com preços acessíveis. $\mathrm{O}$ interesse em conhecer a história do Forte de Tecla, localizado a 500 metros da vinícola, também foi apontada com uma das motivações dos turistas.
A principal motivação que levam visitantes ao

empreendimento pesquisado é: interesse pela história, cultura, tradição local e a curiosidade em se conhecer os modernos processos utilizados pela vinícola, considerando que a mesma é referência na região em inovação e tecnologia aplicadas à vitivinicultura. A busca pela experiência no ambiente rural também foi apontada como uma motivação por parte dos turistas.

As principais limitações identificadas na pesquisa foram: a falta de infraestrutura turística no município onde se encontra localizada a vinícola.

A distância dos grandes centros, a falta de sinalização nas principais vias de acesso e a falta de interesse por parte do poder público em estimular o turismo na região também foram apontadas como limitações para desenvolvimento do enoturismo.

\section{A empresa considera} o fluxo de turistas na vinícola como um grande benefício para a empresa. Em geral os visitantes são procedentes de cidades próximas, da capital do estado ou visitantes que realizam viagens programadas. A empresa possui um sistema de banco de dados que realiza o cadastro de todos que visitam a vinícola. Todos os cadastrados participam de ações promocionais e de divulgações institucionais.

A empresa possui como meta o aumento da quantidade de visitantes na vinícola, que de acordo com o diretor da empresa pode ocorrer pela existência de um mix de atividades diferenciadas oferecidas aos visitantes e também pela produção de vinhos de qualidade.
A empresa considera o fluxo de turistas na vinícola como um grande benefício para a empresa. Em geral os visitantes da vinícola são oriundos da Serra Gaúcha, da capital do estado, da Região Metropolitana e de alguns países, como Uruguai e Argentina. O controle de visitantes é feito através de um livro de registros. Não existem processos informatizados neste processo.
A empresa considera o fluxo de turistas na vinícola como um grande benefício para a empresa.

Não existem processos informatizados que viabilizem

o controle do fluxo de

viajantes que visitam a

empresa. Segundo a respondente o controle do fluxo de turistas é realizado de forma manual e é utilizado apenas para controle interno da empresa.
Não se aplica.

Não se aplica. 


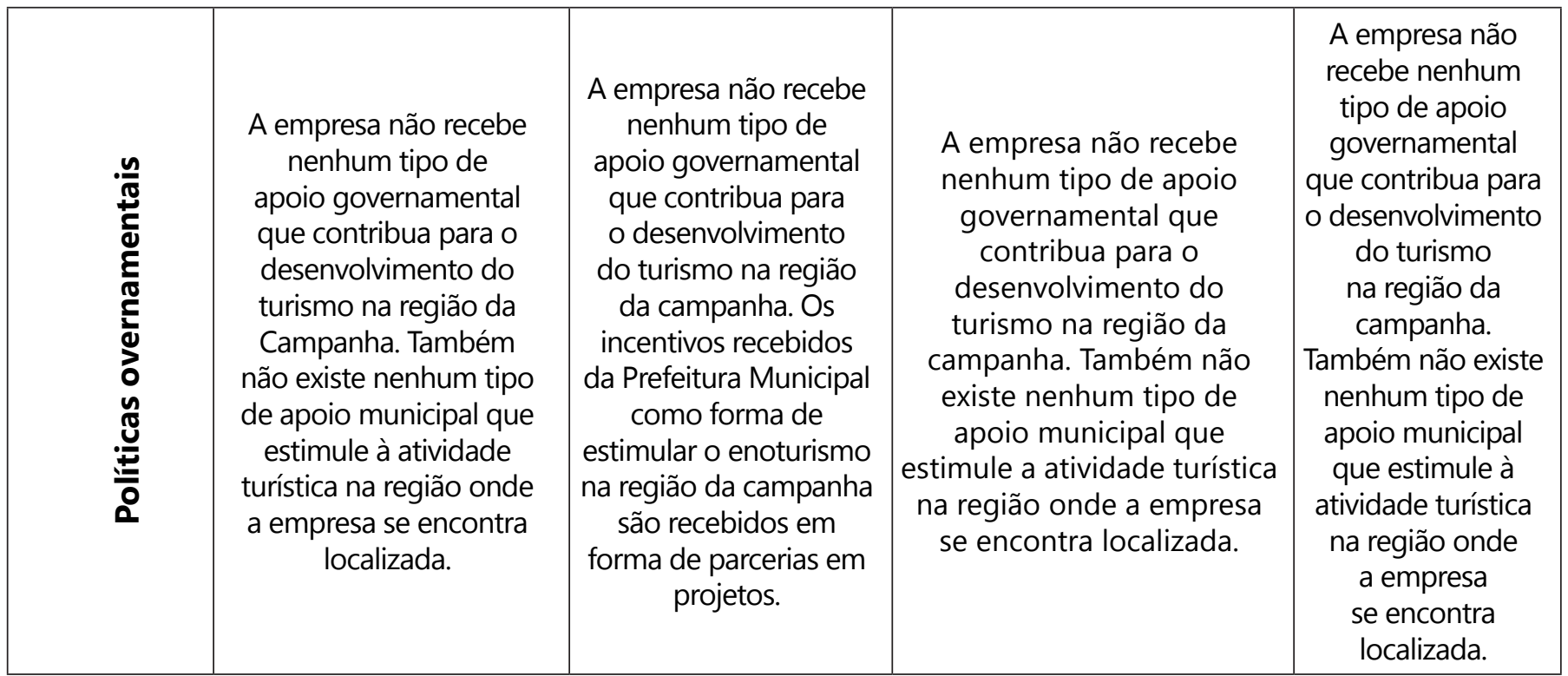

Fonte: Elaborado pelo Autor (2016).

\section{ANÁLISE DOS DADOS DA PESQUISA}

Os resultados desta pesquisa ratificaram o enoturismo como uma promissora ferramenta de desenvolvimento econômico a ser considerada pelos empresários do segmento de vitivinicultura na região da campanha gaúcha. Os empreendimentos pesquisados estão localizados em regiões rurais e apenas um deles não recebe turistas. Desta forma, evidencia-se o caráter rural das empresas atuantes no mercado enoturístico. Estes dados ratificam os estudos de Quadri - Felitti e Fiori (2012) e Alonso e Lio (2010).

O interesse em conhecer os processos que envolvem a produção de vinhos, assim como o funcionamento de uma vinícola juntamente com o desejo da realização de uma experiência diferenciada foram as principais motivações identificadas na pesquisa. Neste sentido os autores Cho et al (2014) afirmam que os processos de fabricação de vinhos, assim como a degustação dos mesmos no ambiente onde são produzidos estão na lista das principais motivações dos apreciadores do turismo do vinho.

Para Grybovych et al (2013) todas estas atividades fazem parte de um conjunto de experiências propiciadas pelo enoturismo. Os atores afirmam ainda que estas experiências são influenciadas por fatores tais como o ambiente, a paisagem, o clima e a cultura local. 
A pesquisa identificou que $75 \%$ dos empreendimentos pesquisados oferecem como principais atividades aos turistas: degustações, refeições temáticas, trilhas e visitações a vinícolas e vinhedos. Todas estas atividades vão encontro dos estudos de Hall et all (2000) e Alonso e Liu (2010) quando afirmam que o enoturismo corresponde a uma atividade que tem o vinho como principal atrativo. Clemente-Ricolfe et al (2010) corroboram este pensamento afirmando que a diversificação na oferta de serviços aos turistas do vinho permitem que a empresa torne-se mais competitiva, adquirindo chances reais de satisfazer a expectativa de seus clientes.

Para os $75 \%$ pesquisados que já aderiram ao enoturismo em seus empreendimentos, este cumpre bem o papel de apresentar novos arranjos administrativos agregando mais valores aos negócios do vinho. Autores como Vitorino et al (2013) apontam que a vantagem competitiva - o conjunto de características que permitem um empreendimento diferenciar-se pela melhor entrega de valor aos seus clientes, em comparação aos seus concorrentes e sob o ponto de vista dos fregueses - torna uma empresa diferente para melhor na perspectiva do consumidor final deste produto turístico, identificando propriedades específicas e combinações individuais de produtos e mercados em suas respectivas áreas de negócio, oportunizando à empresa destacável posição.

Para um dado segmento de mercado, a vantagem competitiva é a razão pela qual os seus clientes escolhem a oferta da empresa, produtos ou serviços, e não a concorrência disponível no mesmo mercado de atuação, exatamente porque sua oferta é vista como única, ou melhor. Ela tem o mesmo conceito do "Reconhecimento" apresentado nos 5Rs.

Ela é sempre relativa a possibilidades ou posição dentro do seu mercado ou segmento de atuação: atendimento; conhecimento; criatividade; inovação. E se os concorrentes também oferecem em mesmas condições, algo que seria uma vantagem passa a ser obrigação.

Assim, a empresa $D$, que ainda está fora da oferta desse segmento de turismo em vinícolas da Campanha, deverá implementar o quanto antes as visitas de turistas para experiência do vinho em suas propriedades rurais. Para ser considerada vantagem a prática deve realçar a sua oferta sobre os 
demais. A vantagem competitiva pode apresentar-se em ser única, melhor, ou ser diferente.

O respondente da empresa $D$, o único que ainda não aderiu ao enoturismo em seu empreendimento, sabe que necessitará dos recursos e da capacidade de infraestrutura para implementar e fornecer o diferencial para os clientes de forma constante e consistente.

Referente à categoria "Mercado", observou-se que a empresa B e a empresa $C$ iniciaram o negócio de enoturismo no mesmo ano de 2013 sob o discurso de terem identificado o potencial dessa prática de enoturismo. A empresa A só engajou a atividade turística após dois anos que as empresas $B$ e $C$ já estavam desenvolvendo este segmento de enoturismo em suas propriedades na região da Campanha Gaúcha.

Estas duas empresas ( $\mathrm{B}$ e $\mathrm{C}$ ) possuem parcerias, sendo que a empresa $\mathrm{B}$ iniciou suas atividades ligadas ao enoturismo através de parceria com ente municipal - a prefeitura do Município e o DNIT - Departamento Nacional de Infraestrutura de Transportes, autarquia federal brasileira vinculada ao Ministério dos Transportes.

A empresa B e a empresa $C$ têm parceria com empresas específicas do setor turístico: agência de viagens e operadores de turismo para promoção e venda de seu produto turístico, o enoturismo na região da Serra Gaúcha.

A empresa A entrou no mercado após possuir infraestrutura necessária, e a empresa $D$ ainda não está ofertando este produto turístico pela crença de não haver ainda a infraestrutura necessária para a promoção de serviços ligados ao turismo do vinho, visto que a propriedade não somente é dedicada ao cultivo e fabrico da bebida, mas está localizada dentro de outro empreendimento.

A empresa D mostra um perfil diferenciado das demais, enquanto as outras vinícolas recebemos visitantes turistas, ela recebe grupo específico, conhecedores e imprensa - profissionais, enólogos e jornalistas em visitas pré-agendadas. No item mercado, a empresa $C$ parece estar em vantagem competitiva, visto que trabalha na captação de clientela por meio de ferramentas de promoção.

As empresas pesquisadas que desenvolvem atividades ligadas ao turismo do vinho consideram em sua totalidade o fluxo de turistas como um grande 
benefício no processo de comercialização de seus produtos, assim como na promoção de suas empresas. Estes dados são ratificados pelas pesquisas de Getz e Brown (2006) quando afirmam que o enoturismo converte-se em uma forte ferramenta de competitividade capaz de contribuir diretamente para a promoção do destino, assim como no processo de comercialização dos produtos produzidos pelas empresas envolvidas.

Gomez et al (2013) explicam a necessidade de infraestruturas adequadas para o desenvolvimento do turismo do vinho. Os dados da pesquisa apontam como principal limitação para implementação do enoturismo a falta de infraestrutura de acesso, considerando que grande parte das vinícolas estão inseridas em áreas rurais. Outra limitação identificada é falta de infraestrutura turística dos municípios onde estão localizados os empreendimentos. Para Gomez et al (2013), o enoturismo contribui diretamente no desenvolvimento regional destes destinos a partir do momento em que exige construção de infraestrutura mínima para recebimento de turistas.

O turismo do vinho beneficia não apenas os empreendimentos que recebem visitantes. O fluxo de turistas nas localidades propicia impactos econômicos em toda a cadeia produtiva do turismo através do seu efeito multiplicador.

Os entrevistados descrevem o enoturismo como um dos eixos de sustentação do desenvolvimento econômico da região da Campanha e da Fronteira Oeste. Trata-se de uma emergente atividade econômica já implantada e com possibilidades reais de crescimento. Estes dados confirmam os estudos de MarzoNavarro e Pedraja-Iglesias (2012) quando afirmam que o enoturismo emerge em nível mundial como promissora atividade econômica capaz de transformar regiões produtoras de vinhos localidades turísticas. A região da Campanha Gaúcha atualmente possui 16 vinícolas e cerca de 70\% destes empreendimentos recebem visitantes em suas instalações, ratificando os estudos de Ashton et al (2015), que colocam o Brasil na rota enoturística dos países sul-americanos.

\section{CONCLUSÕES, LIMITAÇÕES E PESQUISAS FUTURAS}

A Região da Campanha Gaúcha desponta no cenário regional e nacional como uma promissora região produtora de vinhos. Neste cenário, o enoturismo surge como uma atividade econômica rentável, com potencial para impulsionar 
o turismo e o desenvolvimento regional. Diferentemente de produtos como o arroz e a soja, que são característicos da região da campanha, o vinho estimula o consumidor final a visitar os locais onde são produzidos e a conhecer os seus diversos processos de produção.

O turismo do vinho é um segmento relativamente novo, contudo, devido ao seu rápido crescimento, e reconhecida relevância econômica para diversas destinações turísticas ou não, tem chamado atenção da comunidade acadêmica para realização de pesquisas que busquem uma melhor compreensão acerca do fenômeno.

O enoturismo tem sido determinante no processo de desenvolvimento de algumas localidades rurais, que não possuem alternativa que contribua com o seu desenvolvimento econômico. Este trabalho teve como objetivo analisar de que forma o Enoturismo enquanto atividade econômica contribui para o desenvolvimento de vinícolas localizadas na Região da Campanha no estado do Rio Grande do Sul - Brasil.

Os resultados da pesquisa ratificam o enoturismo como uma alternativa econômica consolidada implementada pelas empresas pesquisadas na região da Campanha Gaúcha, impactando direta e indiretamente a cadeia produtiva do turismo. As principais limitações da pesquisa estão relacionadas com a dificuldade de obtenção de dados primários junto aos empreendimentos pesquisados e de dados secundários em instituições governamentais, que, uma vez disponibilizados, trariam importantes contribuições para esta investigação.

A localização geográfica da Região da Campanha Gaúcha torna-se um determinante limitador para o desenvolvimento do Enoturismo na região. Uma vez localizada distante dos grandes centros e da capital, exige por parte do turista uma prévia programação de viagem com disponibilidade de permanência de no mínimo uma semana, período este necessário para realização dos deslocamentos inerentes à viagem, assim como para que sejam realizadas as visitas aos empreendimentos.

A principal contribuição desta investigação é identificada a partir do momento em que se percebe que há falta de trabalhos formais, que busquem compreender o funcionamento do fenômeno enoturismo na região da Campanha Gaúcha. 
Sugere-se a realização de novas pesquisas sobre a temática utilizando como unidades de análises uma população maior de empreendimentos localizados na região da Campanha. Estudos comparativos tomando como base outras regiões produtoras de vinhos no Brasil e no exterior também devem ser considerados.

\section{REFERÊNCIAS}

ACADEMIA DO VINHO. Disponível em: <http://www.academiadovinho.com.br/_regiao_ mostra.php?reg_num=CAMPANHA.> Acesso em: 11 mai. 2016.

Alonso, A. D.; Liu, Y., (2010). "Wine tourism development in emerging Western Australian regions", International Journal of Contemporary Hospitality Management, Vol. 22 Iss 2. p. $245-262$

Ashton, M. S. G., Valduga, V., \& Tomazzoni, E. L. (2015). Turismo criativo e desenvolvimento da oferta turística do cluster do Vale dos Vinhedos (RS, Brasil). Investigaciones Turísticas, (10), 90-116.

Bruwer, J. (2003). "South African wine routes: some perspectives on the wine tourism industry'sstructural dimensions and wine tourism product". Tourism Management, Vol. 24 No. 2002, p. 423-435.

Carlsen, J., \& Boksberger, P. (2015). Enhancing consumer value in wine tourism. Journal of Hospitality \& Tourism Research, 39(1), 132-144.

Conforto, E. C.; Amaral, D. C.; Silva, S. L. D. (2011). Roteiro para revisão bibliográfica sistemática: aplicação no desenvolvimento de produtos e gerenciamento de projetos. $\mathbf{8}^{\circ}$ Congresso Brasileiro de Gestão de Desenvolvimento de Produto - CBGDP. Anais. p.112,. Porto Alegre.

Byrd, Erick T.; Canziani, Bonnie; HSIEH, Yu-Chin (Jerrie); SEVIL, Keith Debbage Sonmez. (2016) Wine tourism: Motivating visitors through core and supplementary services. Tourism Management 52, p. 19 e 29.

Cauchick Miguel, P. A. (Org.). (2012). Metodologia de pesquisa em engenharia de produção e gestão de operações. (2 ed.). Rio de Janeiro: Elsevier.

Clemente-Ricolfe, J.-S. Escriba-Peréz, C. Rodriguez-Barrio, J.-E.; and Buitrago-Vera, J.-M. (2012). The potential wine tourist market: the case of Valencia (Spain). Journal of Wine Research. Vol. 23, No. 2, July 2012, $185-202$ 
Dawson H.; Holmes, M.; Jacobs, H. And W., Richard I. Flick, U. (2004). Uma introdução à pesquisa qualitativa (2 ed.). Porto Alegre: Bookman.

FRANCO, M. L. P. B. (2005). Análise de conteúdo. 2. ed. Brasília: Líber Livro Editora.

Getz, D., \& Brown, G. (2006). Critical success factors for wine tourism regions: A demand analysis. Tourism Management 27, p. $146-158$.

Gómez, M. Molina, A. Esteban, A. (2013). What are the main factors attracting visitors to wineries? A PLS multi-group comparison. Qual Quant 47, p. 2637-2657

Grybovych, O. Lankford,. Lankford, S. (2013). "Motivations of wine travelers in rural Northeast Iowa", International Journal of Wine Business Research, Vol. 25 Iss 4, p. 285 - 309.

Hall, C.M., Sharples L, Cambourne, B, Macionis, N (2000). Wine Tourism Around the World Development, Management and Markets. Elsevier, Butterworth-Heinemann, Oxford, UK.

Hall, C.M.; Johnson, G; Cambourne, B; Macionis, N; Mitchell, R. And Sharples, L. (2000) Wine tourism: an introduction. In: HALL, C.M.; LONGO, A.M.; MITCHELL, R. and JOHNSON, G. (eds). Wine Tourism Around the World: Development, Management and Markets. Oxford: Elsevier, p. 1-23

Hanqin, Z. Q. J. (Jessica); Haobin, Y. B.; Hung, Y. K., (2013). "Wine tourism phenomena in China: an emerging market", International Journal of Contemporary Hospitality Management, Vol. 25 Iss 7, p. $1115-1134$

Hojman, D. E., \& Hunter-Jones, P. (2012). Wine tourism: Chilean wine regions and routes. Journal of Business Research, 65(1), 13-21.

Jones, M. F., J.; Singh, N.; Hsiung, Y. (2015). Determining the critical success factors of the winw tourism region of napa a from supply perspective. International Journal of Tourism Research, 7(1). 261-271.

Koch, J. Martin, A. Nash, R. (2013). "Overview of perceptions of German wine tourism from the winery perspective", International Journal of Wine Business Research, Vol. 25 Iss 1, p. 50 - 74

López-Guzmán, T.; Rodríguez García, J., Vieira Rodríguez, Á. (2013). Revisión de la literatura científica sobre enoturismo en España. Cuadernos de Turismo, núm. 32, juliodiciembre, p. 171-188 
López-Guzmán, T., Rodríguez-García, J., Sánchez-Cañizares, S., Luján-García, M, J. (2011). "The development of wine tourism in Spain". International Journal of Wine Business Research, Vol. 23 Iss 4, p. $374-386$.

Marzo-Navarro, M.; Pedraja-Iglesias, M. (2012) "Critical factors of wine tourism: incentives and barriers from the potential tourist's perspective", International Journal of Contemporary Hospitality

Meehee, C.; Bonn, M. A; Brymer, R. A. (2014). A Constraint-Based Approach to Wine tourism market segmentation. Journal of Hospitality \& Tourism Research, 201X, Vol. XX, No. X, Month, $1-30$

Mitchell, R. And Hall, C.M. (2006). "Wine tourism research: the state of play".Tourism Review International, Vol. 9 No. 4, pp. 307-322.

Navarro, M. M.; Iglesias, M. P. Desarrollo del turismo del vino desde la perspectiva de los productores: una primera aproximación al caso de Aragón-España. Estudios y perspectivas en turismo, v. 21, n. 3, p. 585-603, 2012.

Quadri-Felitti, D.; Fiore, A. M. (2012). Experience economy constructs as a framework for understanding wine Tourism. Journal of Vacation Marketing. Vol. 18 (1), pp. 3-15.

Secretaria De Turismo, Esporte E Lazer Do Rio Grande Do Sul. Disponível em: <http://www. turismo.rs.gov.br/regiao/5/pampa>. Acesso em: 3 mai, 2016.

Tomasetti, A.; Festa, G. (2014). An Analysis of Wine Tourism in Italy from a Strategic ServiceBased Perspective. Service Science 6(2), p. 122-135.

Vinícola Província De São Pedro. Disponível em: <http://www.redvin.com.br/\#!campanha-gacha/ceut.>. Acesso em: 18 abr. 2016.

Vitorino Filho, V.; Peresin, A.; Leite, G.; Sacomano Neto, M. (2013). Vantagem competitiva: uma releitura teórica de Porter. In: Convibra Administração (Estratégia Empresarial). Disponível em: http://www.convibra.org/upload/paper/adm/adm_2472.pdf. Acessado em: 24 mar. 2016.

Voss, C., Tsikriktsis, N., \& Frohlich, M. (2002). Case Research in Operations Management. International Journal of Operations \& Production Management, 22(2), 195-219

Dawson, H., Holmes, M., Jacobs, H., \& Wade, R. I. (2011). Wine tourism: Winery visitation in the wine appellations of Ontario. Journal of Vacation Marketing, 17(3), 237-246.

Yin, R. K. (2010). Estudo de caso: planejamento e métodos (4 ed.). Porto Alegre: Bookman. 
Zanini, T. V.; Rocha, J..M.. (2010). O Enoturismo no Brasil: um estudo comparativo entre as regiões vinícolas do Vale dos Vinhedos (RS) e do Vale do São Francisco (BA/PE). Revista Turismo e Análise - Volume 21. N. 1 - p. 68-88.

\section{Contribuição dos autores na construção do artigo}

Barbosa: Estruturação da temática, redação e pesquisa de campo. Lacerda: Revisão do texto, contribuição na estruturação da Metodologia utilizada.

Viegas: Revisão das referências utilizadas na Revisão da literatura. Santos: Contribuição nas análises e discussão dos resultados apresentados. 